\title{
PERSPEKTIF KEADILAN IKLIM DALAM INSTRUMEN HUKUM LINGKUNGAN INTERNASIONAL TENTANG PERUBAHAN IKLIM
}

\author{
Deni Bram \\ Fakultas Hukum Universitas Pancasila \\ E-mail: deni_up@yahoo.co.id
}

\begin{abstract}
The issue of climate change has become a central point of attention the world community on this century. In scientists view says that if we fail to make significant reductions in greenhouse gas emissions for ten to twenty years ahead, we face the possibility of harmful environmental disaster at the end of this century. Legal instruments at international level which is present as a step to mitigate climate change were felt only in the interests of developing countries alone that puts the asymmetric advantage. The concept of climate justice is felt not touched so that the regime to combat climate change often fail in the fulfillment of justice for present and future.
\end{abstract}

Keywords: climate change, intergenerational equity, intra generational equity.

\begin{abstract}
Abstrak
Isu mengenai perubahan iklim telah menjelma menjadi titik sentral perhatian masyarakat dunia abad ini. Dalam pandangan para ilmuwan dikatakan bahwa jika kita gagal membuat penurunan yang signifikan pada emisi gas rumah kaca selama sepuluh sampai dua puluh tahun ke depan, kita menghadapi kemungkinan bencana lingkungan membahayakan pada akhir abad ini. Instrumen hukum pada tataran internasional yang hadir sebagai langkah penanggulangan perubahan iklim pun dirasakan hanya menjadi kepentingan negara maju semata yang mengedepankan keuntungan asimetris. Konsep keadilan iklim dirasakan tidak tersentuh sehingga rejim penanggulangan perubahan iklim kerap gagal dalam pemenuhan keadilan bagi saat ini dan saat yang akan datang.
\end{abstract}

Kata kunci: perubahan iklim, keadilan antar generasi, keadilan inter generasi

\section{Pendahuluan}

Salah satu isu lingkungan hidup yang memberikan pengaruh signifikan terhadap semua komponen kehidupan dan sistem kehidupan banyak kalangan saat ini adalah mengenai fenomena perubahan iklim (climate change). ${ }^{1}$

\footnotetext{
Menurut Konvensi Kerja Perserikatan Bangsa-Bangsa tentang Perubahan Iklim (United Nation Framework Convention on Climate Change atau UNFCCC), sistem iklim dalam hubungannya dengan perubahan iklim didefinisikan sebagai totalitas atmosfer, hidrosfer, biosfer, dan geosfer dengan interaksinya. Sedangkan perubahan iklim dinyatakan sebagai perubahan pada iklim yang dipengaruhi langsung atau tidak langsung oleh aktivitas manusia yang mengubah komposisi atmosfer, yang akan memperbesar keragaman iklim teramati pada periode yang cukup panjang. Satu hal yang tidak dapat dipungkiri adalah bahwa pada abad 20, temperatur rata-rata bumi naik $0,4-0,8^{\circ} \mathrm{C}$. Kenaikan ini diduga akan terus berlangsung, dan pada tahun 2100 temperatur rata-rata global akan menjadi $1,4-5,8^{\circ} \mathrm{C}$ lebih hangat. Isu perubahan iklim merupakan salah satu isu yang menjadi
}

Perubahan iklim hadir sebagai suatu bentuk fenomena kerusakan lingkungan yang memiliki dampak pada hampir setiap bidang kehidupan yang mengancam eksistensi kehidupan manusia baik pada tataran lokal, nasional dan juga pada tataran global. ${ }^{2}$

perhatian besar setiap negara di dunia, bahkan salah seorang ilmuwan terkemuka asal Inggris, Sir David King, mengatakan bahwa isu perubahan iklim lebih mengkhawatirkan daripada isu terorisme. Lihat dan bandingkan dengan Arum Siwiendrayanti, "Perubahan Iklim dan Pengaruhnya terhadap Sektor Kese-hatan", J urnal Kesehatan Masyarakat Vol. 3 No. 1 2007, Universitas Negeri Semarang, hlm.17-26; Lihat juga Herman Haeruman, "Perspektif Kebijakan Terkait Perubahan Iklim dan Dampaknya Terhadap Ekonomi", J urnal Ekonomi Lingkungan, Vol. 13 No. 1 2009, Pusat Studi Ekonomi dan Lingkungan Kementerian Lingkungan Hidup, hlm. 15-32

Saat ini tidak ada lagi pertanyaan mengenai apakah pemanasan global terjadi dan juga perdebatan serius tentang apakah aktivitas manusia adalah penyebab dari fenomena iklim yang terjadi. Dalam pandangan para 
Berdasarkan hasil laporan tahunan rutin yang disampaikan pada forum Inter governmental Panel on Climate Change (IPCC) pada $6 \mathrm{Ap}$ ril 2007 yang berjudul Climate Change 2007: Impacts, Adaptation and Vulnerability, dituangkan beberapa proyeksi ilmiah dampak dari perubahan iklim yang akan terjadi secara masif di beberapa negara secara berbeda, antara lain di benua Afrika, antara 75 dan 250 juta orang yang diproyeksikan akan menghadapi peningkatan air stres akibat perubahan iklim pada tahun 2020. Produksi pertanian, termasuk akses ke makanan, diproyeksikan akan sangat membahayakan dan hal ini akan berdampak buruk mata pencaharian, keamanan pangan dan memperparah gizi buruk di seluruh benua Afrika. ${ }^{3}$

Dampak yang diperkirakan terjadi di Benua Asia diproyeksikan akan timbul dari proses pencairan gletser di sekitar pegunungan Himalaya yang akan mengakibatkan banj ir besar dan mempengaruhi sumberdaya air dalam dua hingga tiga dekade mendatang. Fenomena ini akan diikuti oleh arus sungai yang menurun dan mempengaruhi ketersediaan air tawar di kawasan Asia Tengah, Asia Selatan, Asia Timur dan Asia Tenggara dan memberikan dampak kepada lebih dari satu miliar orang pada tahun 2050. Sedangkan untuk negara-negara kepulauan yang terletak di sekitar garis khatulistiwa diproyeksikan akan menerima dampak dari kenaikan permukaan air laut yang akan menyebabkan majunya garis pantai dan akan mempengaruhi aktivitas secara keseluruhan.

Dampak perubahan iklim yang nyata akan terjadi dalam konteks Indonesia adalah kenaikan muka air laut setinggi satu meter yang akan mengakibatkan masalah besar pada masyarakat yang tinggal di daerah pesisir. Abrasi dan mundurnya garis pantai sampai beberapa kilometer menyebabkan banyak masyarakat kehilangan

ilmuwan dikatakan bahwa jika kita gagal membuat penurunan yang signifikan pada emisi gas rumah kaca selama sepuluh sampai dua puluh tahun, kita menghadapi kemungkinan bencana lingkungan membahayakan pada akhir abad ini. Lihat J oko Parwata, "90 Persen Bencana Terkait Perubahan Iklim", Warta Geologi Vol. 3 No. 3 2008, Badan Geologi Bandung, hlm. 32-33

3 Lihat Intergovernmental Panel on Climate Change (IPCC) Report, Climate Change 2007: Impacts, Adaptation and Vulnerability. tempat tinggal dan sumber daya. Beberapa hasil penelitian menunjukkan bahwa kenaikan permukaan air laut setinggi $60 \mathrm{~cm}$ akan berpengaruh langsung terhadap jutaan penduduk yang hidup di daerah pesisir. Panjang garis pantai Indonesia yang lebih dari $80.000 \mathrm{~km}$ memiliki konsentrasi penduduk dan kegiatan sosial ekonomi masyarakat yang tinggi, termasuk kota pantai dan pelabuhan. Demikian juga ekosistem alami seperti mangrove akan banyak mengalami gangguan dari pelumpuran dan penggenangan yang makin tinggi. ${ }^{4}$

Uraian data ilmiah mengenai akibat yang dihasilkan dari perubahan iklim sebagaimana tertuang dalam paragraf di atas secara jelas menggambarkan bahwa dampak dari perubahan iklim telah terjadi secara nyata saat ini dan berimbas pada masa yang akan datang. Eksistensi Negara-negara kepulauan yang semakin terancam serta dampak simultan yang akan dialami oleh negara-negara miskin menjadi cerminan ketidakadilan iklim bagi saat ini. ${ }^{5}$ Pada masa yang akan datang, kondisi sekarang ini turut andil dalam memperburuk iklim yang akan dirasakan oleh generasi ke depan.

Di tengah derasnya informasi serta proyeksi ilmiah mengenai betapa hebatnya dampak dari perubahan iklim terhadap ekosistem bumi,

\footnotetext{
4 Kerusakan kawasan pantai akan mengakibatkan hilangnya Iahan potensi dengan nilai ekonomis dan ekologi yang sangat besar. Salah satu kawasan pantai yang telah mengalami kerusakan adalah Pantai Kalianda yang terletak di Teluk Lampung Kabupaten Lampung Selatan. Kawasan ini sudah tidak terlindungi oleh hutan bakau dan mengalami abrasi pantai yang cukup tinggi. Pantai ini juga telah mengalami erosi akibat perubahan arah gelombang. Lihat Cahya Sujatmiko, "Studi Penanggulangan Abrasi Pantai Kalianda", Jurnal Sains dan Inovasi Vol. 5 No. 1 tahun 2009, Lembaga Penelitian Universitas Sang Bumi Ruwa J urai, hlm. 6-16

5 Perubahan iklim global yang berlangsung saat ini memberikan pengaruh pada berbagai bidang, termasuk perikanan yang menyebabkan terjadinya degradasi lingkungan perairan. Hal ini berdampak pada muncul dan menyebarnya berbagai penyakit ikan, menurunnya laju pertumbuhan organisme perairan, bahkan hingga menimbulkan kematian massal ikan. Lihat Tri Heru Prihadi, Erlania, Iswari Ratna Astuti, "Kajian Dampak Lingkungan Global dari Kegiatan Keramba Jaring Apung Melalui LCA", J urnal Riset Akuakultur Pusat Riset Perikanan Budidaya, hlm. 263-273; Lihat juga Geoffrey Lean, Disappearing World: Global Warming Claims Tropical Island, The Independent, Dec. 24, 2006, terdapat dalam situs www.independent.co.uk/ environment/climatechange/ disappearing-world-global-warming-claimstropical-island-429764.html. diakses 5 Februari 2011
} 
terdapat pendapat lain yang mengambil sisi berseberangan dengan mainstream yang berkembang. Bjorn Lomborg dalam karya fenomenalnya The Skeptical Environmentalist's menarik perhatian beberapa kalangan pemikir lingkungan hidup dengan menyatakan secara tegas bahwa isu perubahan iklim tidak cukup signifikan untuk ditangani secara serius dengan ketentuan yang mengatur secara ketat dan tegas. Bahkan Lomborg dengan manifesto berupa Copenhagen Consensus menempatkan isu penurunan jumlah emisi karbon dalam nomor urut 30 (tiga puluh) dari 30 (tiga puluh) masalah global yang dihadapi dunia saat ini. ${ }^{6}$

Lomborg dalam hipotesanya menggunakan perhitungan secara ekonomis sampai pada kesimpulan bahwa masalah perubahan iklim bukanlah masalah serius yang dihadapi dunia saat ini. Bahkan dengan pengaturan yang terdapat di dalam Protokol Kyoto secara tegas mengenai limitasi jumlah emisi gas buang Negara-negara akan menanggung biaya yang lebih besar daripada manfaat yang diraih. ${ }^{7} \mathrm{Hal}$ ini sejalan dengan hasil penelitian yang dilakukan oleh Wigley pada tahun 1996 yang menyatakan bahwa efektifitas dari Protokol Kyoto sekarang ini patut diragukan sebagai salah satu instrumen awal penurunan emisi gas rumah kaca. Dalam kesimpulannya, Wigley berpendapat bahwa lebih baik mengedepankan "doing nothing policy" dalam menghadapi perubahan iklim. ${ }^{8} \mathrm{Hal}$ ini pun menjadi perdebatan menarik di kalangan pemerhati lingkungan mengenai validitas dari ancaman perubahan iklim yang terjadi.

6 Bjorn Lomborg, 2008, Copenhagen Consensus 2008 Results., terdapat dalam situs www.copenhagen consensus. com diakses pada tanggal 25 April 2011.

Dalam karya Lomborg lainnya, mengutip hasil penelitian yang dilakukan oleh Nordhaus dan Boyer pada tahun 2000 tergambarkan bahwa mekanisme penurunan nilai emisi gas rumah kaca yang terdapat dalam instrumen Protokol Kyoto hanya mampu memberikan sumbangsih minimal dibandingkan dengan tanpa adanya Protokol Kyoto. Lihat Marsudi Triatmodjo, "Implikasi Berlakunya Protocol Kyoto-1997 Terhadap Indonesia", Jurnal Hukum Internasional Vol. 2 No. 2 tahun 2005, Lembaga Pengkajian Hokum Internasional Universitas Indonesia, hlm. 294-310

8 Lihat T.M.L. Wigley, et.al., "Economic and Environmental Choices in the Stabilization of Atmospheric $\mathrm{CO} 2$ Concentration", Nature, Vol.379, J anuary, hlm. 379.
Tonggak kepedulian masyarakat internasional terhadap perubahan iklim selanjutnya diwujudkan dalam hasil Konferensi Tingkat Tinggi di Rio de Jainero melalui suatu instrumen United Nations Framework Convention on Climate Change (UNFCCC) yang menjadi suatu bentuk keseriusan masyarakat internasional untuk menentukan tujuan bersama dan rencana strategis penanggulangan perubahan iklim. $^{9}$ Negara-negara yang tergabung dalam UNFCCC kemudian sepakat untuk menstabilkan konsentrasi gas rumah kaca anthropogenik sebagai sumber utama dari perubahan iklim dan untuk menghindari gangguan dari sistem iklim dengan mengendalikan penyebab utama berupa metan, asam nitrat, khususnya emisi karbon dioksida. ${ }^{10}$

Kehadiran Protokol Kyoto yang semula di harapkan dapat memberikan kontribusi dalam usaha penurunan nilai emisi gas rumah kaca yang memicu terjadinya perubahan iklim, ternyata tidak dapat memberikan hasil yang memuaskan. Hal ini paling tidak disebabkan oleh beberapa hal, pertama, lemahnya keikutsertaan dan komitmen Amerika Serikat sebagai negara yang memiliki sumbangsih dalam peningkatan emisi CO2 dari sektor bahan bakar fosil. ${ }^{11}$ Selanjutnya, Protokol Kyoto juga tidak dapat berperan maksimal pada saat negara-negara Annex I yang diharapkan menjadi subyek utama dalam usaha penanggulangan perubahan iklim justru merumuskan kebijakan-kebijakan pada

9 Lihat United Nations Framework Convention on Climate Change (UNFCCC), "Climate Change Information Kit: The International Response to Climate Change Information" Sheet 17.

10 Angela Churie et al., Summary of the Eighteenth Sessions of the Subsidiary Bodies of the UN Framework Convention on Climate Change, 12 Earth Negotiations Bull.

11 Tercatat pada tahun 2005 Amerika Serikat bersumbangsih sebanyak $21 \%$ dari total emisi keseluruhan. Terlepas dari kegagalan dari Protokol Kyoto, kehadiran protokol ini paling tidak memberikan 2 (dua) sumbangsih utama bagi perkembangan hukum lingkungan internasional yaitu; Pertama, Protokol Kyoto menjadi tonggak awal kerangka hukum dalam penanggulangan masalah perubahan iklim pada khususnya dan masalah lingkungan hidup pada tataran global pada umumnya. Kedua, secara politis keberadaan Protokol Kyoto menjadi langkah signifikan yang menunjukkan kepedulian masyarakat internasional terhadap permasalahan perubahan iklim dan solusi ke depan yang ditempuh. Lihat Bruce Pardy, 2004, "The Kyoto Protocol: Bad News for the Global Environment", Journal of Environmental Law and Practice, hlm. 1. 
skala lokal dan nasional yang justru tidak mendukung dari Protokol Kyoto dan membuat target penurunan konsentrasi gas rumah kaca menjadi sulit untuk dicapai. ${ }^{12}$ Akhirnya, besarnya kepentingan yang termuat dalam proses pembuatan dan pelaksanaan mekanisme penataan yang termuat dalam Protokol Kyoto semakin memberikan antipati dalam usaha penanggulangan perubahan iklim. ${ }^{13}$

Masa depan tentang rezim perubahan iklim saat ini berada dalam kondisi yang problematis. Keberadaan Protokol Kyoto yang akan segera berakhir pada tahun 2012 serta perdebatan seputar kehadiran instrumen hukum dan mekanisme yang telah dilakukan dalam beberapa tahun belakangan membuat beberapa kalangan akademisi dan ilmuwan mempertanyakan terhadap efektifitas pasca Protokol Kyoto untuk menurunkan nilai konsentrasi gas rumah kaca yang dihasilkan dari kegiatan manusia. ${ }^{14}$

Secara umum eksistensi dari hukum internasional yang pada awalnya hanya berada dalam pemikiran hukum di masa lalu mulai dipertanyakan untuk kepentingan saat ini dan saat yang akan datang. ${ }^{15}$ Kehadiran instrumen hukum lingkungan internasional pada umumnya dan yang menyangkut pada bidang perubahan iklim pada khususnya dirasakan tidak memberikan sumbangsih yang simetris baik pada kondisi saat ini dalam belahan dunia yang berbeda, maupun dalam kondisi yang bersifat lintas waktu yaitu antara kepentingan saat ini dan saat

12 Konsensus yang disepakati pada tahun 2004 adalah kewajiban untuk menurunkan nilai emisi gas rumah kaca sebesar 5,2\% dari nilai emisi yang ada pada tahun 1990 . Lihat Miranda A. Schreurs, "Competing Agendas and the Climate Change Negotiations: The United States, the European Union, and Japan", 31 Environmental Law. Report. 2001.

13 Kritik lain yang mengungkapkan proyeksi kegagalan Protokol Kyoto didasari oleh pemahaman bahwa Protokol Kyoto hanya memberikan limitasi dan target penurunan emisi yang relatif sedikit bagi negara - negara maju. Hal ini pun diperburuk dengan keengganan dari negara maju dalam mencapai target penurunan emisi. Seiring dengan waktu dampak terhadap perubahan iklim akan segera dihadapi dan kebijakan Protokol Kyoto akan dirasakan terlambat.

14 Lihat Feng Gao, The International Climate Regime: Where Do We Stand?, in The Kyoto Protocol and Beyond., hlm. 7-8.

15 Lihat E. Brown Weiss, "The Planetary Trust: Conservation and Intergenerational Equity," 11 Ecology Law. Quarterly. Vol. 295 1984, akan datang. Kondisi inilah yang kemudian menjadi perhatian pada pemerhati di bidang lingkungan internasional bahwa kebijakan perubahan iklim yang hadir saat ini sering kali menjadi instrumen yang mengakomodir kepentingan negara maju semata dan tidak mengakomodir semangat dalam keadilan iklim. ${ }^{16}$

Mencermati hal di atas, maka dalam diskursus perubahan iklim, wacana yang berkembang adalah meningkatkan kepedulian dari masyarakat internasional termasuk peran yang diharapkan dari negara-negara berkembang dalam usaha perbaikan iklim. Namun, dalam beberapa indikasi awal dapat terlihat adanya ketidakadilan dalam kristalisasi kepedulian yang dituangkan dalam perjanjian internasional di bidang perubahan iklim. Hal inilah yang menjadi perhatian utama dalam pembahasan artikel ini untuk menguji validitas dari perjanjian internasional di bidang perubahan iklim dalam perspektif keadilan iklim.

\section{Keadilan Iklim: Now and Beyond}

Permasalahan seputar perubahan iklim telah menyentuh suatu kondisi yang multidimensional dengan kompleksitas yang tinggi di bidang ilmu pengetahuan, ekonomi dan keadilan. Saat ini perhatian banyak dituangkan dalam dampak dari perubahan iklim terhadap sektor ekonomi dan ilmu pengetahuan, namun pembahasan dalam perspektif keadilan terhadap kondisi iklim jarang mendapat perhatian yang serius. Konsep keadilan dalam dimensi lingkungan hidup menjadi suatu pembahasan yang bersifat lintas sektoral dan lintas kepentingan. Dalam perspektif keadilan lingkungan, kondisi geografis setiap negara merupakan suatu ketentuan yang harus diperlakukan bijaksana dan hak untuk mendapatkan lingkungan hidup yang baik dan sehat adalah hak asasi manusia. ${ }^{17}$

16 Lihat juga M. Daud silalahi, "Peranan dan Kedudukan Hukum Lingkungan Internasional Dewasa Ini", Jurnal Hukum Internasional Vol. 2 No. 2 Tahun 2005, Lembaga Pengkajian Hukum Internasional Universitas Indonesia, hlm. 249-265.

17 Lihat J oseph W. Dellapenna, "International Law's Lessons for the Law of the Lakes", $40 \mathrm{U}$. Michigan J ournal Law Reform 747, 791 \& n. 274, 792 (2007),; Lihat pula, Equal Rights, Governance, and the Environment: Integrating Environmental Justice Principles in Corporate 
Perubahan iklim telah memperumit isuisu tentang pembagian sumber daya di antara generasi-generasi masa kini dan juga generasi yang akan datang. Ketika jalan satu-satunya menuju sumber daya yang dapat diperbaharui adalah lewat pengelolaan dan pemeliharaannya di dalam kondisi yang dapat diperbaharui, ekosistem hutan kini sedang dihancurkan oleh hujan asam dan pemanasan global. Pengendalian emisi karbon anthropogenik jelas memerlukan solusi internasional untuk menghindarkan malapetaka utama dan mencegah subversi kepada ekosistem yang sudah tua. Pelaksanaan komitmen ini secara nyata mengharuskan semua negara menurunkan emisi yang ada, pada saat yang bersamaan negara-negara yang sedang berkembang dapat mengklaim secara rasional bahwa masalah muncul sebagian besar dari negara-negara maju yang selama ini menggunakan energi yang memicu emisi untuk maksud-maksud praktis.

Kondisi ekosistem bumi yang tidak terikat pada suatu batas administratif wilayah serta keterkaitan antara kondisi saat ini dengan proyeksi keadaan iklim ke depan menjadikan konsep keadilan lingkungan bertitik tumpu pada 2 (dua) konsep utama yaitu keadilan inter generasi dan keadilan antar generasi. ${ }^{18}$ Terdapat 2 (dua) relevansi penting dalam pembahasan mengenai keadilan inter generasi yang diungkapkan oleh pemikir di bidang ekologi manusia, yaitu hubungan antara manusia dengan spesies mahluk hidup lainnya dan hubungan antara manusia dengan sistem lingkungan yang manusia terdapat di dalamnya. Terciptanya keadilan lingkungan secara umum dalam lintasan pemikiran filosofis membutuhkan suatu netralitas sebagai dasar pijakan utama. Oleh karena itu,

Social Responsibility, 33 Ecology Law Quarterly. 443, $470 \&$ nn 2006, hlm. 153

18 Dalam mendefinisikan keadilan inter generasi akan sangat berguna jika menganggap komunitas manusia sebagai suatu bentuk kemitraan yang bersifat lintas generasi. Edmund Burke mendefinisikan negara sebagai suatu bentuk kemitraan dalam pemikirannya Burke mengemukakan bahwa "as the ends of such a partnership cannot be obtained in many generations, it becomes a partnership not only between those who are living but between those who are living, those who $* 200$ are dead, and those who are to be born." Lihat E. Burke, 1790, Reflections on the Revolution in France pembahasan mengenai keadilan inter generasi tidak hanya berkutat pada kenyataan perlindungan generasi yang akan datang untuk mendapatkan hak terhadap lingkungan yang layak semata, namun juga menyentuh pembahasan mengenai kondisi bumi yang proporsional sebagai kaidah dasar moral. ${ }^{19}$

Konsep keadilan inter generasi telah berkembang dalam pergumulan hukum internasional pada umumnya. Hal ini dapat diindikasi dalam Pembukaan dalam Universal Declaration of Human Rights yang berisi, "Whereas recognition of the inherent dignity and of the equal and inalienable rights of all members of the human family is the foundation of freedom, justice and peace in the world." Terminologi "all members" yang digunakan dalam kalimat di atas tentu tidak hanya terbatas pada kondisi saat ini namun juga bersifat pemikiran ke depan dan cita-cita dari hukum internasional yang hendak dicapai. ${ }^{20}$

Konsep keadilan inter generasi dalam perkembangan hukum lingkungan internasional pada khususnya, mulai dibicarakan pada saat persiapan Stockholm Conference on the Human Environment tahun 1972 sebagai pertemuan internasional pertama kali yang membicarakan eksistensi manusia dan lingkungan hidup. ${ }^{21}$ Da-

19 Secara moral, negara-negara maju waj ib menerima kuota dan mematuhi pembatasan emisi yang dirumuskan dalam Protokol Kyoto tanpa mengharapkan itu terlebih dahulu oleh negara - negara berkembang karena mereka perlu melakukan kegiatan yang ditengarai dapat menjadi pemicu emisi dalam rangka memenuhi kebutuhan warga nya. Lihat Laura Westra, 2006, Environmental J ustice and The Rights of Unborn and Future Generations., London : Earthscan, hlm. 135.

20 Kehadiran konsep Keadilan Inter Generasi ini juga secara perlahan diadopsi dalam beberapa dokumen Perjanjian Internasional baik secara umum maupun yang langsung berkaitan dengan lingkungan hidup, seperti: The United Nations Charter, the International Covenant on Civil and Political Rights, the Convention on the Prevention and Punishment of the Crime of Genocide, the American Declaration on the Rights and Duties of Man, the Declaration on the Elimination of Discrimination against Women, the Declaration on the Rights of the Child. Lihat Agora, J anuary 1992, What Obligation Does Our Generation Owe to the Next? An Approach to Global Environmental Responsibility, American Journal of International Law

21 Lihat Conference on the Human Environment, Stockholm, Swed., J une 5-16, 1972, Report of the United Nations Conference on the Human Environment, 3, U.N. Doc. A/ CONF.48/ 14/ REV.1, J une 16, 1972. 
Iam kalimat pembukaan konvensi, beberapa kali ditegaskan secara eksplisit bahwa tujuan yang hendak dicapai dalam konvensi ini adalah terciptanya kondisi lingkungan yang layak untuk saat ini dan masa yang akan datang. ${ }^{22}$ Pembahasan selanjutnya mengenai konsep keadilan inter generasi termuat dalam laporan U.N. World Commission on Environment and Development (WCED) yang dikenal dengan Bruntland Commission Report on Our Common Future yang memberikan definisi keadilan inter generasi secara konkrit dan nyata. Dalam perumusan Burtland Report, keadilan inter generasi menekankan pada konsep pemenuhan kebutuhan saat ini tanpa menelantarkan kebutuhan generasi masa yang akan datang. ${ }^{23}$ Isu keadilan inter generasi ini pun bergulir sampai dengan perhelatan Earth Summit pada tahun 1992 yang menghasilkan Rio Declaration on Environment and Development dan Agenda 21 yang menempatkan eksistensi generasi saat ini dan yang akan datang sebagai prioritas utama. ${ }^{24}$

Secara umum, setiap generasi memiliki 2 (dua) kewajiban utama yang diemban untuk generasi selanjutnya, yaitu pertama kewajiban untuk menghadirkan kondisi lingkungan hidup

22 Lihat Stockholm Declaration, Principe. 1. Dalam tambahannya yang terdapat dalam, Principle 2 dari Stockholm Declaration dikatakan bahwa "the natural resources of the earth, including the air, water, land, flora and fauna, and especially representative samples of natural ecosystems, must be safeguarded for the benefit of present and future generations through careful planning or management, as appropriate.". Pada saat yang hampir bersamaan hadir pula perjanjian internasional yang mengedepankan isu keadilan inter generasi seperti 1972 London Ocean Dumping Convention, 1972 World Cultural and Natural Heritage Convention, 1973 Endangered Species Convention, dan 1974 Charter of Economic Rights and Duties of States, sedangkan pada tataran regional juga terdapat konten sejenis seperti yang dapat ditemui pada 1976 Barcelona Mediterranean Sea Convention. Tonggak kepedulian masyarakat internasional terhadap isu keadilan inter generasi ini juga dituangkan dalam 1982 U.N. World Charter for Nature dan 1997 UNESCO Declaration on Responsibilities Towards Future Generations sebagai dokumen hukum internasional yang secara eksplisit mengemukakan tentang konsep keadilan inter generasi.

23 Lihat Gro Harlem Brundtland Et Al., 1987, Our Common Future: The World Commission On Environment And Development, Our Common Future.hlm.8. Lihat pula WCED report U.N. G.A. Res. 42/ 427.

24 Lihat Conference on Environment and Development, Rio de J aneiro, Braz., J une 13, 1992, Report of the United Nations Conference on Environment and Development, U.N. Doc. A/CONF. 151/26, vol. I, Aug. 12, 1992 yang layak untuk dinikmati oleh generasi yang akan datang sebagaimana digunakan pada saat ini dan kedua, berkewajiban untuk memperbaiki kondisi kerusakan lingkungan yang terjadi sebagai akibat perbuatan generasi terdahulu sebagai upaya untuk menjamin keberlanjutan lingkungan. ${ }^{25}$ Pada tataran paling lemah, setiap generasi dibebani kewajiban moral untuk dapat mewariskan kondisi lingkungan hidup yang paling tidak sama dengan kondisi yang dinikmati saat ini dari generasi terdahulu. Walaupun sangat sulit untuk mencapai suatu titik yang ideal dalam konsep di atas, dalam laporan Inter-governmental Panel on Climate Change (IPCC) usaha maksimal yang dapat dilakukan adalah melakukan proyeksi dampak kerusakan lingkungan yang akan muncul serta upaya alternatif penanggulangan dampak tersebut. ${ }^{26}$

Bersandar pada dua premis utama kewajiban dari setiap generasi yang diungkapkan di atas, hal ini untuk kemudian diderivasikan dalam beberapa variabel khusus yang memuat hak dan kewajiban dari setiap generasi secara khusus. Edith Brown Weiss dalam tulisannya mengemukakan 4 (empat) tugas khusus dari setiap generasi untuk menjamin keberlanjutan iklim yaitu, pertama, memelihara keanekaragaman sumber alam dan budaya yang ada pada saat ini. Kedua, Memelihara kualitas dari lingkungan hidup saat ini untuk dapat dinikmati oleh generasi yang akan datang. Selanjutnya,

25 Lihat Edith Brown Weiss, "The Planetary Trust: Conservation and Intergenerational Equity", 11 Ecology Law. Quarterly Vol. 495 1984; Lihat pula Édith Brown Weiss, "In Fairness to Future Generations", Environment, Apr. 1990, hlm. $23-26$

26 Lihat U.N. Env't Programme \& World Meteorological Org., Intergovernmental Panel on Climate Change [IPCC], IPCC Second Assessment, Climate Change 1995: A Report of the Intergovernmental Panel on Climate Change, 6.7 (Dec. 1995), terdapat dalam situs http:// www.ipcc.ch/ pdf/ climate-changes-1995/ ipcc-2nd-assessment/ 2nd-assessment-en. pdf. Diakses 5 Februari 2011., Lihat pula U.N. Env't Programme \& World Meteorological Org., IPCC, IPCC Fourth Assessment Report, Climate Change 2007: Synthesis Report (2007), Lihat pula Mark Lynas, Six Degrees: Our Future On A Hotter Planet (2007). Untuk melihat informasi secara detil mengenai negara-negara miskin yang terkena dampak serta akibat yang diterima dapat dilihat dalam U.N. Dev. Programme, Human Development Report 2007/2008, Fighting Climate Change: Human Solidarity in a Divided WorId, 2 (2007), terdapat dalam situs http:// hdr.undp.org/ en/ reports/global/ hdr2007-2008 diakses 5 Feb.i 2011. 
menyediakan akses bagi semua komunitas ekosistem bumi untuk dapat menikmati kondisi lingkungan saat ini yang diwariskan dari generasi sebelumnya. Terakhir, menjaga akses yang dimiliki sekarang untuk dapat diberikan kepada generasi yang akan datang. ${ }^{27}$

Tidak semua negara memiliki kemampuan serta potensi yang sama dalam melakukan usah perlindungan lingkungan dan perbaikan lingkungan. Sebaliknya, setiap negara juga memiliki kontribusi yang berbeda dalam perubahan iklim. Menelisik track record sumbangsih dalam perubahan iklim dan inisiatif yang berbeda dari setiap negara tersebut, Edith Brown Weiss mengintrodusir keadilan intra generasi yang merupakan suatu konsep kewajiban antara negara maju kepada negara berkembang atau miskin dalam upaya perbaikan kondisi iklim saat ini untuk kepentingan generasi yang akan datang. ${ }^{28}$

Keadilan intra generasi secara umum dapat diartikan sebagai suatu pemahaman bahwa setiap orang yang berada dalam lingkup satu generasi yang sama memiliki hak dan akses yang sama untuk memperoleh manfaat dari sumber alam yang ada serta dapat memperoleh kondisi lingkungan hidup yang baik dan sehat. ${ }^{29}$ Pengertian lain mengenai konsep keadilan inter generasi hadir sebagai bentuk pemenuhan segala kebutuhan dasar dari manusia yang meliputi lingkungan hidup yang sehat, ketersediaan makanan dan tempat tinggal yang layak serta pemenuhan kebutuhan spiritual dan budaya. Dalam pelaksanaan kebutuhan tersebut, konsep transfer kesejahteraan dan transfer teknologi

$27 \quad$ Ibid. hlm. 38.

28 Lihat Edith Brown Weiss, "Our Rights and Obligations to Future Generations for the Environment", 84 America. J ournal. International Law Vol. 198 year 1990; Lihat pula Edith Brown Weiss, Intergenerational Equity in International Law, 1987 Proc. Annual. Meeting American. Society International Law. 126; Lihat pula Edith Brown Weiss, "The Planetary Trust: Conservation and Intergenerational Equity", 11 Ecology Law Quarterly. Vol. 495 year 1984,; Lihat pula Edith Brown Weiss, Apr. 1990, "In Fairness to Future Generations", Environment, hlm. 2728

29 Lihat Ronnie Harding et al., 1994, Interpretation of the Principles for the Finer Conference on the Environment: Sustainability - Principles to Practice 1., Unisearch: University of New South Wales, hlm.21-29. dari negara kaya kepada negara miskin menjadi salah satu alternatif yang dapat dilakukan. ${ }^{30}$

Konsep keadilan intra generasi dapat dimaknai secara umum dalam konteks nasional maupun dalam konteks internasional. Dalam skala nasional, konsep ini mencoba memberikan akses secara merata kepada seluruh warga negara terhadap sumber daya alam yang ada termasuk di dalamnya air bersih, udara serta pemanfaatan sumber laut. Konsep ini juga dapat digunakan untuk mempertanyakan kembali pemanfaatan sumber daya alam oleh sektor swasta dalam pemanfaatan lingkungan hidup di lingkup nasional. Sedangkan pada tataran internasional, konsep ini menekankan pada kesetaraan alokasi dari udara, air serta keanekaragaman hayati yang terdapat di belahan dunia untuk masing-masing pihak dapat memperoleh manfaat yang sama serta mendayagunakan sesuai dengan kebutuhan dan sistem penyangga kehidupan bumi yang ada. ${ }^{31}$ Bahkan dalam tataran yang lebih ekstrem, konsep keadilan intra generasi menuntut adanya pembatasan konsumsi negara-negara maju dari sumber alam baik berupa air, udara dan barang lainnya. Konsep keadilan intra generasi ini memang disadari atau tidak berhubungan erat dengan komitmen politik dan ekonomi dalam pelaksanaannya. Oleh karena itu, perlu ada kesungguhan komitmen dari masyarakat internasional dalam pelaksanaan konsep keadilan intra generasi terutama dalam perubahan cara pandang dari negara dan pemangku kepentingan internasional. ${ }^{32}$

Konsep keadilan yang menyentuh keadilan inter generasi dan keadilan intra generasi bersifat saling melengkapi satu sama lain dalam rangka menghadirkan suatu hipotesis yang saling terkait satu sama lain. Paling tidak terdapat 3 hipotesis utama yang menggambarkan korelasi antara keadilan inter generasi dan keadilan intra generasi yaitu independensi, fa-

30 Lihat R. Goodland \& G. Ledec, "Neoclassical Economics and Principles of Sustainable Development", 38 Ecological Modeling, 19 (36) year 1987, hlm.10.

31 Lihat Ben Boer Willamette, "Institutionalizing Ecologically Sustainable Development: The Roles of National, State, And Local Governments In Trans-lating Grand Strategy Into Action", Law Review Spring, 1995, hlm.6.

32 lbid. 
silitasi dan persaingan. ${ }^{33}$ Korelasi independensi antara keadilan inter generasi dan keadilan intra generasi diartikan sebagai bentuk kemandirian setiap konsep dalam pencapaian tujuannya masing-masing. Pelaksanaan keadilan yang bersifat intra generasi pada saat ini tidak akan menghilangkan kewajiban dan juga kegagalan untuk mewujudkan tujuan yang dikehendaki oleh keadilan inter generasi.

Kehadiran konsep keadilan inter generasi dan intra generasi dalam tataran fasilitasi, saling mendukung satu sama lain. Pelaksanaan konsep keadilan intra generasi yang dilakukan secara optimal dalam kurun waktu saat ini dalam pemahaman ini dapat menunjang pelaksanaan dan kesempurnaan tujuan dari keadilan inter generasi di masa yang akan datang. ${ }^{34} \mathrm{Se}$ dangkan pada tataran hipotesis persaingan, mengatakan bahwa masing-masing konsep keadilan saling berkompetisi satu sama lain. Hipotesis ini menyatakan secara umum bahwa maksimalisasi dari satu konsep akan mengakibatkan melemahnya konsep keadilan yang lain. ${ }^{35}$

Kehadiran konsep keadilan iklim saat ini mutlak untuk diperhatikan dan dijadikan sebagai landasan idealis untuk perumusan sumbersumber hukum lingkungan internasional. Perjanjian internasional yang hadir dalam rangka kepentingan perubahan iklim saat ini dapat dikatakan sangat minim dalam upaya menciptakan keadilan lingkungan baik dalam tataran keadilan inter generasi maupun dalam tataran keadilan intra generasi. Sebagaimana yang terjadi di banyak negara berkembang, komunitas yang miskin dan terpinggirkan di Indonesia diduga memikul penderitaan akibat efek dari perubahan iklim. Dampak yang diprediksi meliputi curah hujan dan banjir yang lebih hebat, ancaman terhadap ketahanan pangan, ketinggian air laut meningkat yang merugikan masyarakat pantai dan meningkatnya penyakit seperti malaria dan demam berdarah. Sebagai negara

\footnotetext{
33 Lihat Stefanie Glotzbach dan Stefan Baumgartner, The Relationship Between Intragenerational And Intergenerational Ecological Justice. Department of Sustainability Sciences and Department of Economics, Leuphana University. hlm. 2

34 Ibid., hlm. 15

$35 \mathrm{lbid}, \mathrm{hlm} .18$
}

kepulauan, Indonesia rentan terhadap peningkatan ketinggian air laut, badai dan pengelantangan batu karang (coral reef bleaching) yang diakibatkan oleh pemanasan global yang mengancam masyarakat pantai dan penghidupan mereka, baik itu karena pola iklim yang makin tak dapat diperkirakan untuk musim tanam mau pun panen. Laporan terkini tentang Indonesia oleh United Nations Development Programme (UNDP) mendesak agar masalah adaptasi masyarakat miskin terhadap dampak perubahan iklim diberikan perhatian lebih besar.

Laporan berjudul The Other Half of Climate Change memperingatkan bahwa perubahan iklim "meningkatkan risiko dan kerentanan yang dihadapi rakyat miskin, menimbulkan tekanan lebih banyak pada mekanisme pertahanan diri yang sudah menipis" dan "menghambat upaya atau orang miskin untuk membangun kehidupan dengan lebih baik bagi diri sendiri dan keluarga mereka." Yang lebih mengecewakan lagi adalah bahwa para juru runding pemerintah yang menghadiri konferensi Desember Ialu (resminya bertajuk UN Framework Convention on Climate Change $13^{\text {th }}$ Conference of Parties, UNFCCC COP13) tidak dapat mencapai kesepakatan untuk menargetkan penurunan drastis emisi gas rumah kaca yang dibutuhkan sangat mendesak untuk memperlambat perubahan iklim. Uni Eropa, Cina dan sebagian besar negara berkembang mendesak negara-negara kaya untuk memangkas emisi mereka sebesar 25-40\% namun hal ini dihalangi oleh AS. Pada akhirnya, dokumen utama hanya menyatakan bahwa perlu adanya 'pemangkasan besar' pada emisi global.

Salah satu issue yang kerap diperbincangkan dalam diskursus keadilan iklim adalah konsep emisi per kapita. Banyak kalangan setuju bahwa salah satu cara untuk dapat menanggulangi perubahan iklim adalah dengan menentukan batas dari emisi yang dihasilkan oleh suatu negara sehingga memungkinkan untuk dapat menciptakan hak emisi untuk setiap negara. Dalam sistem yang dianut dalam Protokol Kyoto, penurunan angka emisi semata-mata hanya dihitung dengan angka prosentase tanpa mem- 
pertimbangkan jumlah penduduk yang ada, hal ini tentu tidak memberikan suatu keuntungan simetris pada saat negara-negara maju hanya dibebani kewajiban sedangkan negara berkembang dengan jumlah penduduk yang relatif besar dibatasi pula dengan parameter yang sama dengan negara maju. Penghitungan emisi per kapita menjadi salah satu solusi alternatif dalam melakukan derivasi terhadap keadilan intragenerasi dengan memberikan hak emisi yang secara tidak langsung memberikan hak negara untuk berkembang. ${ }^{36}$

Khusus dalam mekanisme yang terdapat dalam perundingan tahunan Conference of the Parties yang merupakan salah satu institusi yang hadir dalam pelaksanaan Protokol Kyoto dapat dikatakan negara-negara maju tidak melihat konsep perubahan iklim sebagai suatu yang krusial. Hal ini paling tidak dapat dilihat dalam perundingan serta negosiasi yang terjadi dalam forum tahunan yang mencerminkan adanya pengarusutamaan dari negara-negara maju untuk memasukkan kepentingan secara parsial. Meruj uk kepada pemahaman Hikmahanto J uwana yang mengidentikkan hukum internasional sebagai salah satu instrumen dari negara-negara maju dalam menekan kepentingan negara berkembang hendaknya ke depan negara-negara berkembang dapat memiliki daya kritis yang lebih tajam dalam melihat keberadaan suatu perjanjian internasional. ${ }^{37}$

\section{Penutup \\ Simpulan}

36 Lihat Declaration on the Right to Development, G.A. Res. 128, U.N. GAOR, 41st Sess., Supp. No. 53, U.N. Doc. A/ 41/53, Dec. 4, 1986

37 Dalam kepentingan Negara Maju seringkali memanfaatkan Hukum Internasional sebagai sarana pengubah konsep untuk dapat mengakomodasi kepentingan dari Negara Maju. Perdebatan mengenai perbedaan cara pandang dari negara maju dan negara berkembang dapat dilihat dalam Hikmahanto J uwana, "Hukum Internasional dalam Konflik Kepentingan ekonomi Negara Berkembang dan Negara Maju"., hlm. 4-5. Sedangkan pembahasan mengenai Hukum Internasional sebagai pengubah konsep dapat dilihat dalam Hikmahanto J uwana, "Hukum Internasional Sebagai Instrumen Politik: Beberapa Pengalaman Indonesia sebagai Studi Kasus"., $\mathrm{hlm}$. 27. Terdapat dalam Hikmahanto Juwana, 2010, Hukum Internasional: Dalam Perspektif Indonesia Sebagai Negara Berkembang, Jakarta: PT Yarsif Watampone.
Konsep keadilan iklim dengan bersandar pada 2 (dua) konsep utama yaitu keadilan inter generasi dan keadilan intra generasi pada konsep kekinian dapat dijadikan salah satu kerangka pemikiran yang mengedepankan kehidupan iklim yang lebih baik. Lemahnya proses akomodasi konsep keadilan iklim baik yang tertuang dalam soft law maupun hard law di sumber sumber hukum internasional dewasa ini dapat dikatakan sebagai suatu bentuk kegagalan institusi dan instrumen hukum untuk dapat bertindak otonom dan mengedepankan konsep keadilan yang tidak hanya sekedar berpijak pada suatu kerangka kepastian semata.

\section{Saran}

Tidak dapat dipungkiri bahwa kepentingan dari Negara-negara maju kerap kali mempengaruhi law making process suatu perjanjian internasional pada umumnya dan bidang perubahan iklim pada khususnya. Eksistensi negara berkembang dengan keterbatasan pengaruh serta limitasi kemampuan secara finansial sebenarnya dapat ditunjang dengan keunggulan sumber daya alam yang dapat meningkatkan posisi tawar dari negara berkembang. Pada saat yang bersamaan konsep keadilan iklim dapat menjadi konsep yang mengawal perumusan mekanisme adaptasi maupun mitigasi dari negaranegara dalam rangkaian upaya penyelamatan iklim yang lebih baik.

\section{Daftar Pustaka}

Agora, "What Obligation Does Our Generation Owe to the Next? An Approach to Global Environmental Responsibility". American Journal of International Law January 1992;

Brundtland et al., Gro Harlem. 1987. Our Common Future: The World Commission On Environment And Development, Our Common Future;

Churie et al., Angela. Summary of the Eighteenth Sessions of the Subsidiary Bodies of the UN Framework Convention on Climate Change. 12 Earth Negotiations Bull;

Conference on Environment and Development. Rio de J aneiro, Braz., J une 13, 1992. Report of the United Nations Conference on 
Environment and Development, U.N. Doc. A/ CONF.151/ 26, vol. I, Aug. 12, 1992

Conference on the Human Environment, Stockholm, Swed., J une 5-16, 1972, Report of the United Nations Conference on the Human Environment, 3, U.N. Doc. A/CONF. 48/ 14/ REV.1, J une 16, 1972;

Declaration on the Right to Development, G.A. Res. 128, U.N. GAOR, 41st Sess., Supp. No. 53, U.N. Doc. A/ 41/53, Dec. 4, 1986;

Dellapenna, Joseph W. "International Law's Lessons for the Law of the Lakes", $40 \mathrm{U}$. Michigan Journal Law Reform 747, 791 \& n. 274, 792 (2007);

Gao, Feng. The International Climate Regime: Where Do We Stand? in The Kyoto Protocol and Beyond;

Glotzbach, Stefanie dan Stefan Baumgartner. The Relationship Between Intragenerational and Intergenerational Ecological J ustice. Department of Sustainability Sciences and Department of Economics. Leuphana University;

Goodland, R. \& G. Ledec, "Neoclassical Economics and Principles of Sustainable Development"; 38 Ecological Modeling19 (36) year 1987;

Haeruman, Herman. "Perspektif Kebijakan Terkait Perubahan Iklim dan Dampaknya Terhadap Ekonomi". Jurnal Ekonomi Lingkungan, Vol. 13 No. 1 2009. Pusat Studi Ekonomi dan Lingkungan Kementerian Lingkungan Hidup;

Harding et al., Ronnie. 1994. Interpretation of the Principles for the Finer Conference on the Environment: Sustainability - Principles to Practice 1. Unisearch: University of New South Wales;

Intergovernmental Panel on Climate Change (IPCC) Report. Climate Change 2007: Impacts, Adaptation and Vulnerability;

J uwana, Hikmahanto. 2010. Hukum Internasional: Dalam Perspektif Indonesia Sebagai Negara Berkembang. Jakarta: PT Yarsif Watampone;

Lean, Geoffrey. Disappearing World: Global Warming Claims Tropical Island, The Independent. Dec. 24, 2006, terdapat dalam situs www.independent.co.uk/ environment/ climate-change/ disappearingworld-global-warming-claims-tropicalisland-429764. html. diakses 5 Februari 2011;
Lomborg, Bjorn. 2008. Copenhagen Consensus 2008 Results. terdapat dalam situs http:// www. copenhagen consensus.com diakses pada tanggal 25 April 2011;

Lynas, Mark. 2007. Six Degrees: Our Future On A Hotter;

Pardy, Bruce. "The Kyoto Protocol: Bad News for the Global Environment", Journal of Environmental Law and Practice 2004;

Parwata, J oko. " 90 Persen Bencana Terkait Perubahan Iklim", Warta Geologi, Vol. 3 No. 3 2008. Badan Geologi Bandung;

Prihadi, Tri Heru; Erlania, Iswari Ratna Astuti. "Kajian Dampak Lingkungan Global dari Kegiatan Keramba Jaring Apung Melalui LCA", J urnal Riset Akuakultur. Pusat Riset Perikanan Budidaya;

Schreurs, Miranda A. "Competing Agendas and the Climate Change Negotiations: The United States, the European Union, and Japan", 31 Environmental Law. Report 2001;

Silalahi, M. Daud. "Peranan dan Kedudukan Hukum Lingkungan Internasional Dewasa Ini", J urnal Hukum Internasional Vol. 2 No. 2 2005, Lembaga Pengkajian Hukum Internasional Universitas Indonesia;

Siwiendrayanti, Arum. "Perubahan Iklim dan Pengaruhnya terhadap Sektor Kesehatan". J urnal Kesehatan Masyarakat, Vol. 3 No. 1 2007. Universitas Negeri Semarang;

Sujatmiko, Cahya. "Studi Penanggulangan Abrasi Pantai Kalianda". J urnal Sains dan Inovasi, Vol. 5 No. 1 2009. Lembaga Penelitian Universitas Sang Bumi Ruwa J urai;

Triatmodjo, Marsudi. "Implikasi Berlakunya Protocol Kyoto-1997 Terhadap Indonesia", J urnal Hukum Internasional, Vol. 2 Vol. 2 2005, Lembaga Pengkajian Hukum Internasional Universitas Indonesia;

U.N. Dev. Programme, Human Development Report 2007/ 2008, Fighting Climate Change: Human Solidarity in a Divided World, 2 (2007), terdapat dalam situs http:// hdr. undp.org/ en/ reports/ global/ hdr2007-2008 diakses 5 Feb.i 2011;

U.N. Env't Programme \& World Meteorological Org., Intergovernmental Panel on Climate Change [IPCC], IPCC Second Assessment, Climate Change 1995: A Report of the Intergovernmental Panel on Climate Change, 6.7 (Dec. 1995), terdapat dalam situs http:// www. ipcc.ch/ pdf/ climate-changes 
1995/ ipcc-2nd-as-sessment/ 2nd-assessmenten.pdf. Diakses 5 Februari 2011;

U.N. Env't Programme \& World Meteorological Org., IPCC, IPCC Fourth Assessment Report, Climate Change 2007: Synthesis Report (2007);

United Nations Framework Convention on Climate Change (UNFCCC). Climate Change Information Kit: The International Response to Climate Change Information. Sheet 17;

Weiss, E. Brown. "The Planetary Trust: Conservation and Intergenerational Equity," 11 Ecology Law. Quarterly Vol. 295 1984;

"In Fairness to Future Generations". Environment Apr. 1990;

Intergenerational Equity in International Law. Proc. Annual. Meeting American. Society International Law. 126 1987;
-.---. "Our Rights and Obligations to Future Generations for the Environment". 84 America. Journal. International Law, Vol. 198 1990;

Westra, Laura. 2006. Environmental J ustice and The Rights of Unborn and Future Generations. London: Earthscan;

Wigley, et.al., T.M.L. "Economic and Environmental Choices in the Stabilization of Atmospheric $\mathrm{CO} 2$ Concentration", Nature Vol. 379, January;

Willamette, Ben Boer. "Institutionalizing Ecologically Sustainable Development: The Roles Of National, State, And Local Governments In Translating Grand Strategy Into Action". Law Review Spring, 1995. 